\title{
Low temperature internal gettering of bulk defects in silicon photovoltaic materials
}

\author{
M. Al-Amin ${ }^{a}$ and J.D. Murphy ${ }^{b^{*}}$ \\ School of Engineering, University of Warwick, Coventry, CV4 7AL, UK \\ am.al-amin@warwick.ac.uk, bjohn.d.murphy@warwick.ac.uk \\ ${ }^{*}$ corresponding author
}

Keywords: Silicon, multicrystalline, gettering, iron, lifetime.

\begin{abstract}
Multicrystalline silicon (mc-Si) substrates are widely used for photovoltaic cells. The minority carrier lifetime in mc-Si is affected by recombination associated with metallic impurities in many forms, such as point-like defects, precipitates and bound to or precipitated at structural defects such as dislocations. We have studied the effect of low temperature annealing on the lifetime and bulk iron concentration in as-received mc-Si wafers from different locations within a block. Lifetime measurements are made using a temporary iodine-ethanol surface passivation technique to minimize the occurrence of bulk hydrogenation which often occurs from dielectric films. In good wafers from the middle of the block the lifetime is reduced by annealing at $400{ }^{\circ} \mathrm{C}$ and $500{ }^{\circ} \mathrm{C}$ in a way which does not correlate with changes in bulk iron concentration. Lifetime improvements occur in relatively poor samples from the top and bottom of the block annealed at $300{ }^{\circ} \mathrm{C}$, and also in samples from the bottom annealed at $400{ }^{\circ} \mathrm{C}$. The improvement in bottom wafers correlates with iron loss from the bulk. Our work shows that under some conditions the lifetime in relatively poor as-grown wafers can be improved by low temperature internal gettering.
\end{abstract}

\section{Introduction}

Directionally-solidified multi-crystalline silicon (mc-Si) is used in around half of photovoltaic solar cells. Cells produced from mc-Si wafers are less efficient than those produced from monocrystalline silicon (mono-Si) wafers, but lower production costs for mc-Si mean that both technologies are viable. Wafers of mc-Si contain high concentrations of impurities and structural defects such as dislocations. Impurities, particularly transition metals, exist in various forms including as point-like defects, in precipitates or bound to dislocations. Defects often provide recombination pathways which reduce the minority carrier lifetime (hereafter referred to as just "lifetime") and hence the conversion efficiency of a solar cell.

The material quality of mc-Si wafers, as measured by the lifetime, varies with position in the cast ingot. In general, the as-grown lifetime is highest in wafers in the middle of the ingot, and is lowest at the top and bottom [1], although the lifetime is also lower at the ingot edges [2]. The as-grown lifetime is improved by impurity gettering (which redistributes impurities to locations in which they are less problematic overall) and passivation (which eliminates the effects of defects without physically removing them), but even after these processes the lifetime in the wafers from the very top and bottom of the ingots is sometimes too low for the wafers to be viable for use in photovoltaic cells. At best these make relatively inefficient cells; at worst these are discarded. Finding ways to improve the material quality at the extrema of ingots is therefore of technological importance.

External gettering processes, such as those based on phosphorus diffusion or aluminium deposition, are effective in mc-Si to an extent (e.g. [3]) and remove impurities from the bulk region of the photovoltaic device. Another approach is to use intentional internal gettering to tie up impurities in localized regions within the bulk of the material, since it is well known that metals interact with extended defects in silicon [4-7]. Effective internal gettering could result in an overall lifetime increase by redistributing the impurities into forms in which the net recombination due to a given impurity concentration is reduced. Whilst internal gettering is in principle possible at high 
temperatures, adding further high temperature steps is potentially costly and care needs to be taken to avoid contamination. This study is into low temperature $\left(\leq 500{ }^{\circ} \mathrm{C}\right)$ internal gettering. Although this potentially requires longer annealing times, the advantage is that the solubility of many impurities is low and so in principle the processing can be performed under non-cleanroom conditions. We note that long low temperature annealing has been demonstrated to improve lifetime in mono-Si $[8,9]$. For mono-Si the gettering probably occurs externally at surfaces $[8,10]$, whereas in mc-Si it is likely that long low temperature annealing will result in internal gettering.

Post growth low temperature annealing has been performed on mc-Si before [11-15]. Krain et al. report a reduction in bulk iron concentration in samples annealed at $300{ }^{\circ} \mathrm{C}$ to $500{ }^{\circ} \mathrm{C}$, consistent with iron diffusion to crystallographic defects [11]. They do not however report bulk lifetime data, nor do they investigate different parts of the ingot in detail. In their study silicon nitride surface passivation was used, and this is likely to have caused bulk hydrogenation (and hence bulk passivation). Recent studies have also questioned whether hydrogen affects the behaviour of interstitial iron itself $[16,17]$ and it is important to note iron is not the only impurity found in mc$\mathrm{Si}$. Another study into internal gettering in mc-Si was performed by Liu and Macdonald who studied the kinetics of iron precipitation at $400{ }^{\circ} \mathrm{C}$ to $700{ }^{\circ} \mathrm{C}$ [14]. They found a systematic decay in bulk iron concentration with annealing time dependent on the initial bulk iron supersaturation. They report limited lifetime data, which perhaps indicate a small improvement upon annealing at $400{ }^{\circ} \mathrm{C}$. Surface passivation was achieved by an oxide layer formed at $1000{ }^{\circ} \mathrm{C}$, which the authors state is unlikely to cause bulk hydrogenation. The high temperature will however have redistributed impurities from their as-grown states. Potential extra variables introduced by surface passivation processing make interpretation of internal gettering effects in mc-Si challenging.

Boulfrad et al. apply low temperature internal gettering $\left(550{ }^{\circ} \mathrm{C}\right)$ after higher temperature annealing $\left(\geq 950^{\circ} \mathrm{C}\right)$ [15]. They report an improvement in carrier lifetime in "red zone" wafers from the bottom of ingots, and explain this in terms of impurity segregation to oxide precipitates nucleated in the high temperature step. Other studies were performed by Pickett and Buonassisi [12] and Rinio et al. [13] who applied low temperature annealing during or after the solar cell fabrication process, respectively. Rinio et al. found the cell efficiency is dependent on the annealing temperature, increasing slowly with temperature until a peak at $\sim 575^{\circ} \mathrm{C}$. At higher temperatures the efficiency decreases fairly sharply with cells annealed at $650{ }^{\circ} \mathrm{C}$ exhibiting lower efficiency than cells which had not been annealed. Pickett and Buonassisi's work showed increased cell efficiencies as a result of an additional $500{ }^{\circ} \mathrm{C}$ anneal after phosphorus diffusion. These studies show long low temperature annealing can have tangible benefits for PV cells. The effect of low temperature annealing on mc-Si is far from being fully understood however.

In this paper we report the preliminary results of a systematic study of internal gettering in asgrown mc-Si. Our methodology should provide more information than some previous studies for several reasons. Firstly, we take into account the vertical location of the wafers within the block to distinguish between initially-good and initially-poor wafers. Secondly, we have attempted to minimize hydrogenation of the sample by using a room temperature temporary liquid surface passivation scheme based on iodine-ethanol (IE) for all lifetime measurements. Consequently we are able to report bulk lifetime values (as well as bulk iron concentrations) on samples which are not annealed at high temperatures during passivation. Thirdly, we are able to correlate changes in recombination rate with changes in bulk iron concentration to establish the role of bulk iron in any lifetime change which occurs. Our long-term aim is to establish the conditions under which a single low temperature internal gettering step can improve relatively poor quality mc-Si wafers.

\section{Experimental methods}

Samples. Wafers were sourced from four different height positions (top (T), top of the middle (MT), bottom of the middle (MB), and bottom (B)) of an edge block from a commercially-grown boron doped mc-Si ingot. The wafers were $156 \times 156 \mathrm{~mm}^{2}$ in size with an initial thickness of $\sim 200$ 
$\mu \mathrm{m}$. Resistivities were in the range $7.5 \Omega \mathrm{cm}$ to $11.5 \Omega \mathrm{cm}$, Neighbouring "sister" samples measuring $39 \times 39 \mathrm{~mm}^{2}$ were cut from each wafer. To remove saw damage samples were chemically treated with a planar etch solution comprising $\mathrm{HF}(40 \%), \mathrm{HNO}_{3}(69 \%)$, and $\mathrm{CH}_{3} \mathrm{COOH}(100 \%)$ in the ratio of 24:58:18.

Surface passivation. Samples were first RCA cleaned then dipped into a $10 \%$ HF solution for 1 minute to remove the native oxide. Samples were then immediately placed in optically-transparent plastic seal bags. A thin uniform layer of $0.1 \mathrm{M}$ iodine-ethanol (I-E) solution was formed on the surfaces and excess solution and air bubbles were squeezed out. Lifetime measurements were made within a few minutes, as soon after this time the surface passivation quality degrades substantially.

Lifetime measurement. Bulk lifetimes were measured by quasi-steady-state photoconductance (QSS-PC) [18] using a Sinton WCT-120 lifetime tester. Bulk iron concentrations were determined using a method based on photodissocation of FeB pairs described in Ref. [19], with the first measurement made with the bulk iron in the form of $\mathrm{FeB}$ pairs which were then dissociated by intense illumination followed by the second measurement made immediately afterwards with the iron in the interstitial $\left(\mathrm{Fe}_{\mathrm{i}}\right)$ state. Spatially-resolved PL images on I-E passivated samples were also acquired at each processing stage using a BT Imaging LIS-L1 system which uses 650nm excitation and a silicon charge-coupled device (CCD) camera. These were cross-calibrated using the QSS-PC data to give calibrated lifetime images, with a spatial resolution of $\sim 160 \mu \mathrm{m}$.

Thermal processing. After each lifetime measurement stage samples were cleaned in methanol and subjected to an RCA clean to remove residues of the I-E solution. Samples were annealed in nitrogen at $300{ }^{\circ} \mathrm{C}, 400{ }^{\circ} \mathrm{C}$ or $500{ }^{\circ} \mathrm{C}$ in a tube furnace followed by a rapid cool to room temperature. After annealing samples were again RCA cleaned and then were stored in the dark for at least 36 hours. This is known to be sufficient time for re-association of FeB pairs [19, 20]. Samples were then subjected to the same surface passivation treatment and lifetime measurement procedure described above, then the process was repeated many times for each sample.

\section{Results}

Average bulk lifetime measurements. Lifetime measurements are reported as a function of annealing time at different temperatures in Fig. 1 and Fig. 2. Lifetime is reported at an excess minority carrier density of $1 \times 10^{15} \mathrm{~cm}^{-3}$ with bulk iron in the interstitial state and so is denoted by $\tau_{F_{i}}$. As the starting lifetimes in the samples at the extrema of the block ( $\mathrm{T}$ and $\mathrm{B}$ ) are lower than those in the middle (MT and MB) the data are presented on separate graphs with different scales in Fig. 1 and Fig. 2 respectively. Lifetime values are assumed to be accurate to $\pm 8 \%$ [21].

The starting (as-grown) average bulk lifetimes vary substantially with sample location from the block. For the samples studied here, the initial lifetimes plotted are in the range $9 \mu$ s to $12 \mu$ s for the bottom (B), $60 \mu$ s to $77 \mu$ s for the bottom middle (MB), $32 \mu$ s to $38 \mu$ s for the top middle (MT), and $17 \mu \mathrm{s}$ to $21 \mu \mathrm{s}$ for the top $(\mathrm{T})$. The starting lifetime for each sample is plotted as a horizontal line on each graph so the effects of annealing relative to the starting condition are easily visible. Low temperature annealing generally affects the lifetime, with both increases and decreases observed. General trends with location and temperature are summarized qualitatively in Table 1.

Fig. 1 and Fig. 2 also show plots of the average bulk iron concentrations (determined by photodissocation of FeB pairs) as a function of annealing time at different temperatures. The initial bulk iron concentrations (plotted horizontally) are $2.9 \pm 0.7 \times 10^{12} \mathrm{~cm}^{-3}$ for the bottom (B), $1.9 \pm 0.6$ $\times 10^{11} \mathrm{~cm}^{-3}$ for the bottom middle (MB), $4.0 \pm 1.3 \times 10^{11} \mathrm{~cm}^{-3}$ the top middle (MT), and $1.1 \pm 0.3 \times$ $10^{12} \mathrm{~cm}^{-3}$ for the top (T). General trends are also summarized qualitatively in Table 1.

Fig. 3 shows representative spatially-resolved lifetime images for two samples measured with bulk iron in the form of FeB pairs with I-E passivation. Fig. 3 (a) shows a sample from the bottom (B) improved by annealing at $300{ }^{\circ} \mathrm{C}$. The in-grain lifetime improves with annealing. Fig. 3 (b) shows a sample from the top middle (MT) generally worsened by annealing at $500{ }^{\circ} \mathrm{C}$. 

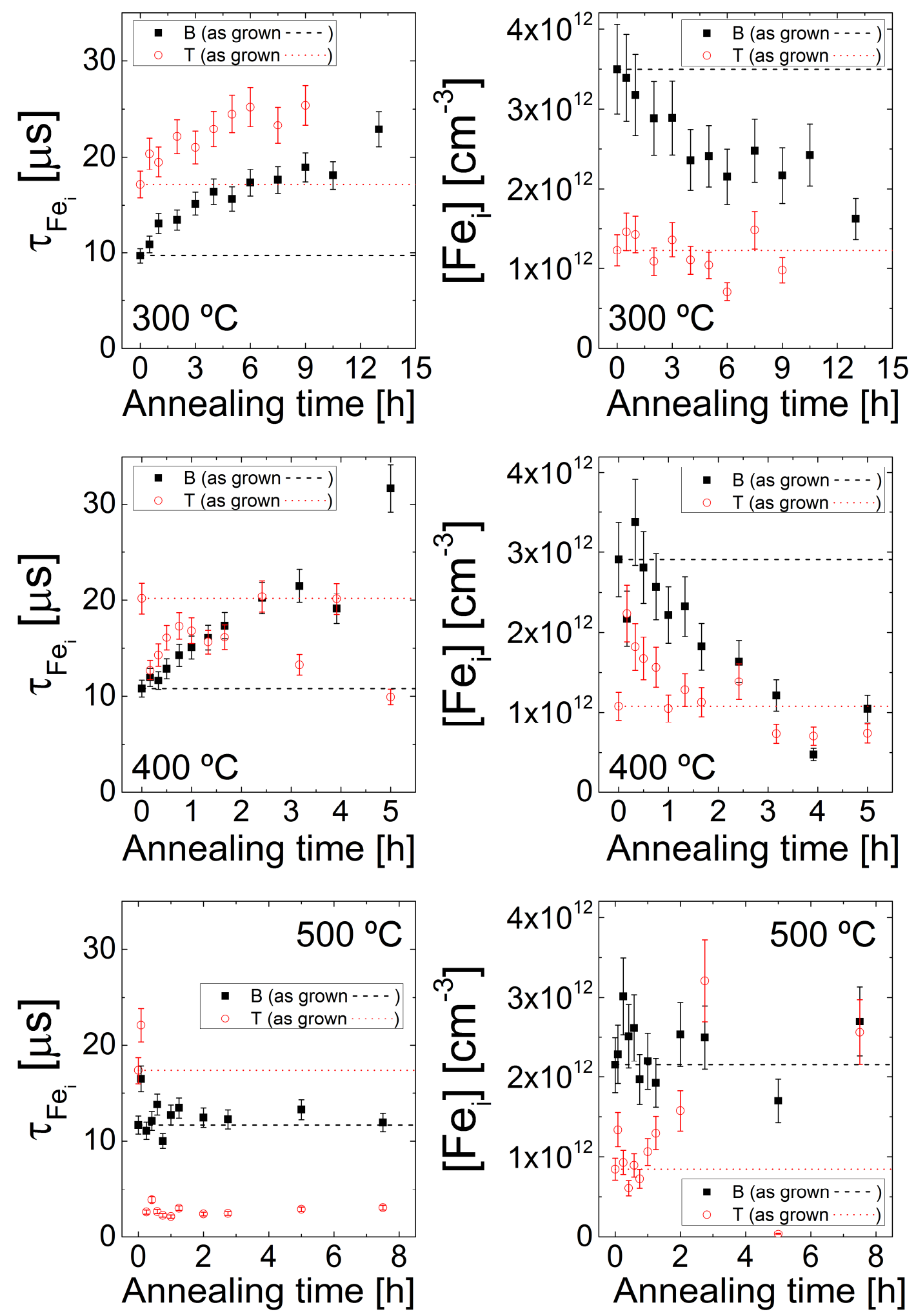

Figure 1. Data from mc-Si samples from the bottom (B) and top (T) of the ingot annealed for the times plotted at $300{ }^{\circ} \mathrm{C}, 400{ }^{\circ} \mathrm{C}$ or $500{ }^{\circ} \mathrm{C}$. The left-hand graphs show minority carrier lifetime at an excess minority carrier density of $1 \times 10^{15} \mathrm{~cm}^{-3}$ with bulk iron in the interstitial state $\left(\tau_{\mathrm{Fe}_{i}}\right)$. The right-hand graphs show interstitial iron concentration measured by photodissociation of FeB pairs. The dotted/ dashed lines are the initial values. 

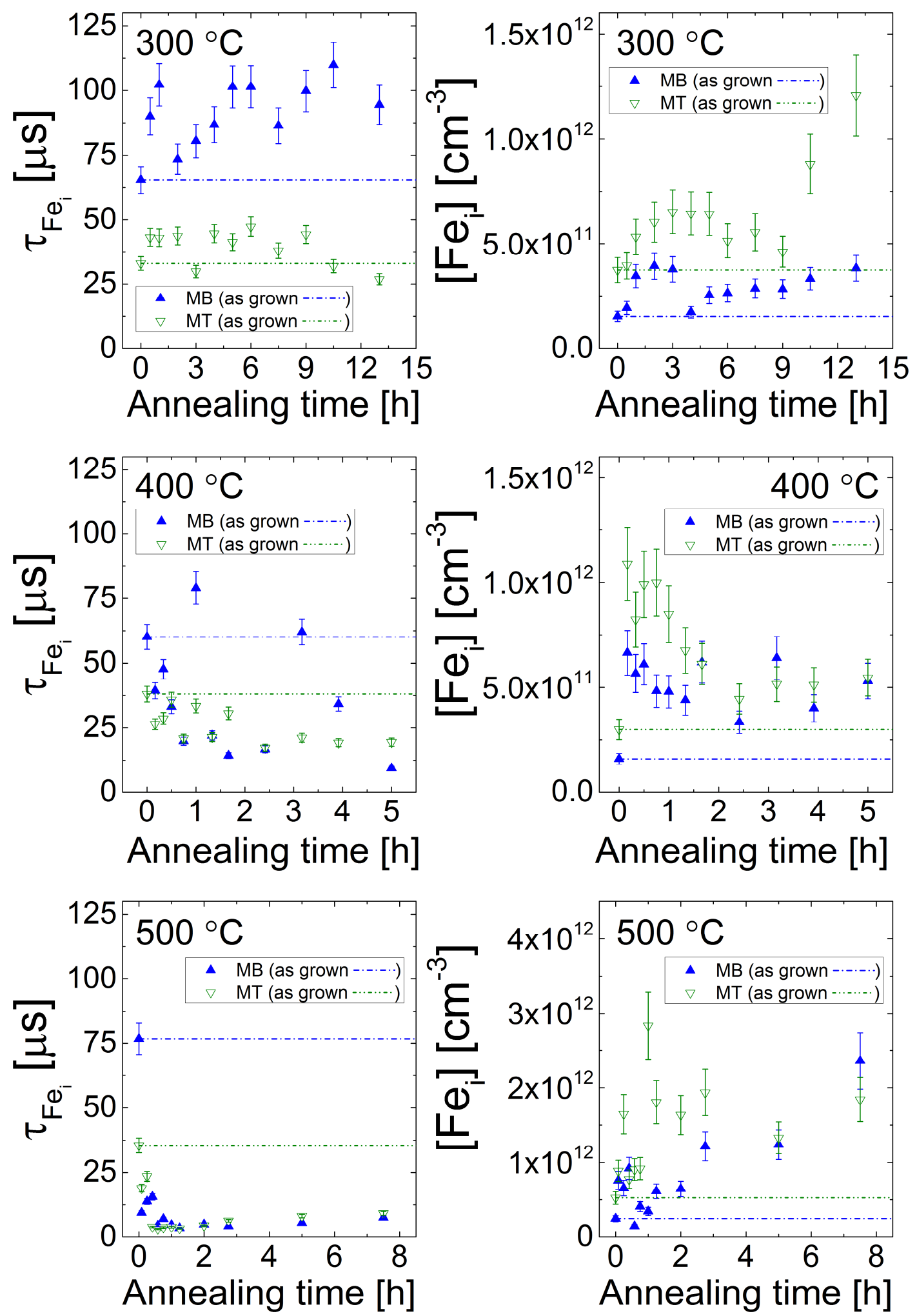

Figure 2. Data from mc-Si samples from the bottom middle (MB) and top middle (MT) of the ingot annealed for the times plotted at $300{ }^{\circ} \mathrm{C}, 400{ }^{\circ} \mathrm{C}$ or $500{ }^{\circ} \mathrm{C}$. The left-hand graphs show minority carrier lifetime at an excess minority carrier density of $1 \times 10^{15} \mathrm{~cm}^{-3}$ with bulk iron in the interstitial state $\left(\tau_{F_{i}}\right)$. The right-hand graphs show interstitial iron concentration measured by photodissociation of FeB pairs. The dotted/ dashed lines are the initial values. 
(a) Bottom $\left(300^{\circ} \mathrm{C}\right)$
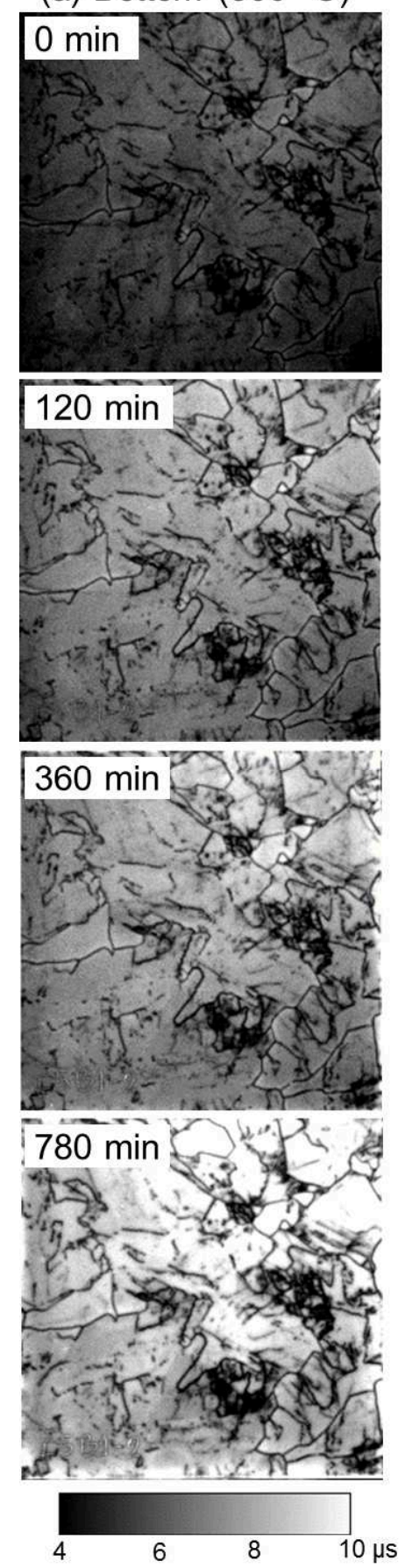

(b) Middle top $\left(500^{\circ} \mathrm{C}\right)$
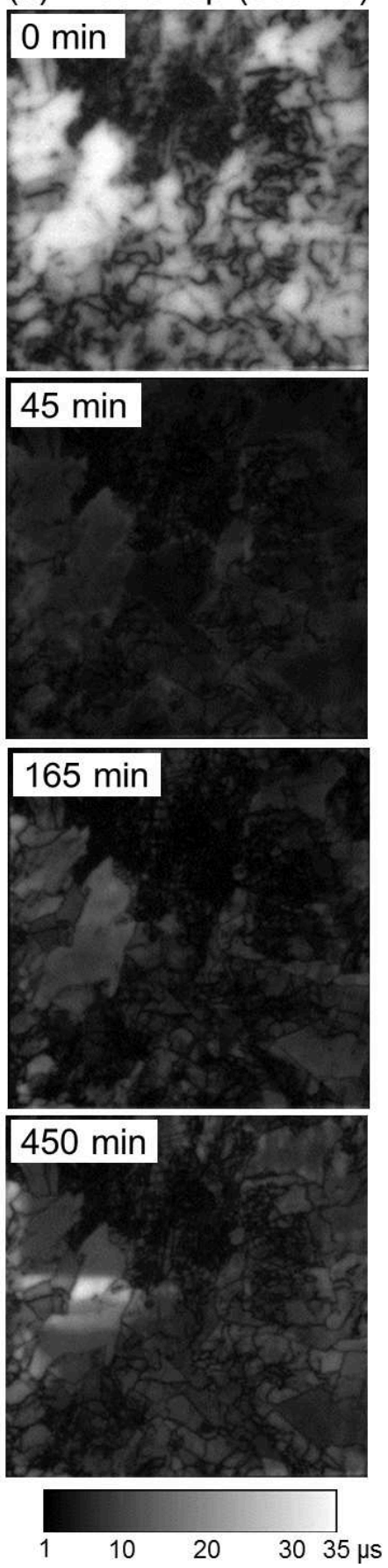

Figure 3. Lifetime images acquired with bulk iron in the FeB state for mc-Si samples: (a) from the bottom of the block (B) annealed at $300{ }^{\circ} \mathrm{C}$ for the times indicated; and (b) from the top of the middle of the block (MT) annealed at $500{ }^{\circ} \mathrm{C}$ for the times indicated. Both samples measure $39 \mathrm{~mm}$ by $39 \mathrm{~mm}$.

\section{Analysis}

We can analyse the data in Fig. 1 and Fig. 2 to determine whether interstitial iron reconfiguration gives rise to the lifetime change by considering the correlation between the normalized change in recombination rate after annealing for time $t$ with the normalized change in interstitial iron concentration. This correlation can be written as: 


$$
\frac{\frac{1}{\tau_{F e_{i}}(t)}-\frac{1}{\tau_{F e_{i}}(0)}}{\frac{1}{\tau_{F e_{i}}(0)}}=A\left(\frac{\left[F e_{i}\right](t)-\left[F e_{i}\right](0)}{\left[F e_{i}\right](0)}\right)
$$

where $A$ is a proportionality function. Fig. 4 shows plots in accordance with Equation 1 from samples annealed at different temperatures from different parts of the mc-Si block. If $A$ takes the value 1 then there exists a 1:1 correlation between the normalized recombination rate change and the normalized bulk iron change, and this is indicated by the diagonal dashed lines on the graphs.

Fig. 4 shows a good correlation for samples from the bottom of the block annealed at $300{ }^{\circ} \mathrm{C}$ and $400{ }^{\circ} \mathrm{C}$, and a possible correlation at $500{ }^{\circ} \mathrm{C}$. For samples from other parts of the block there is not a $1: 1$ correlation between the normalized bulk iron change and the normalized recombination rate change. For the bottom of the block it is therefore likely that the improvements in lifetime found at $300{ }^{\circ} \mathrm{C}$ and $400{ }^{\circ} \mathrm{C}$ arise from an effect associated with bulk iron. The situation for bottom wafers annealed at $500{ }^{\circ} \mathrm{C}$ is less clear-cut, and more data are required. For top wafers improved by annealing at $300{ }^{\circ} \mathrm{C}$ there is not good correlation with the bulk iron changes. For the samples in which there is a substantial reduction in lifetime upon annealing there is very poor correlation, which implies that bulk iron-related effects alone cannot explain the effect observed.

\section{Discussion}

The aim of our work was to establish how mc-Si from different parts of a block responds to long low temperature annealing. Our liquid passivation technique was intended to minimize the introduction of bulk hydrogen into the samples, and by re-passivating the same samples after every thermal process we are able to measure bulk lifetimes. The initial results show the situation is very complicated.

In many cases, perhaps surprisingly, low temperature annealing results in a substantial deterioration in bulk lifetime. This is particularly evident in the material from the middle of the block, in which the relatively high starting lifetimes were reduced significantly by annealing at 400 ${ }^{\circ} \mathrm{C}$ and substantially by annealing at $500{ }^{\circ} \mathrm{C}$. For instance the lifetime in the bottom middle sample was reduced from $77 \mu$ s to below $10 \mu$ s by annealing for just 5 minutes at $500{ }^{\circ} \mathrm{C}$. Similar abrupt lifetime reductions were found at $500{ }^{\circ} \mathrm{C}$ for samples from the top, and top middle (but not the ingot bottom). Data in Fig. 4 demonstrate that the lifetime reductions did not generally correlate with changes in bulk iron concentration, so we attribute the lifetime change to formation of another recombination centre. The lifetime images in Fig. 3 (b) shows a worsening of lifetime in the bulks of the grains. At this stage we cannot be specific about the nature of any centres which may be forming. We do however note that annealing samples at the bottom of the ingot at $500{ }^{\circ} \mathrm{C}$ does not result in a sharp reduction in lifetime, so any explanation would need to account for this observation. A speculative explanation could be that the bulk oxygen concentration is higher at the bottom [15] and that this plays a role in stabilizing the defect at $500{ }^{\circ} \mathrm{C}$.

Lifetime reductions from short annealing at $500{ }^{\circ} \mathrm{C}$ do not seem to have been observed by many, and this could be because of a difference between surface passivation schemes used. Silicon nitride surface passivation typically introduces hydrogen into the bulk [16] and this could passivate the centre which forms. We note that Rinio et al. find an improvement in cell efficiency and internal quantum efficiency after annealing at $500{ }^{\circ} \mathrm{C}$ [13], and a cell efficiency improvement was achieved with a 30 minute anneal at $500{ }^{\circ} \mathrm{C}$ after phosphorus diffusion by Pickett and Buonassisi [12]. These improvements could be due to either hydrogen passivation or external gettering of impurities during cell processing. We are currently performing additional experiments using silicon nitride surface passivation. 


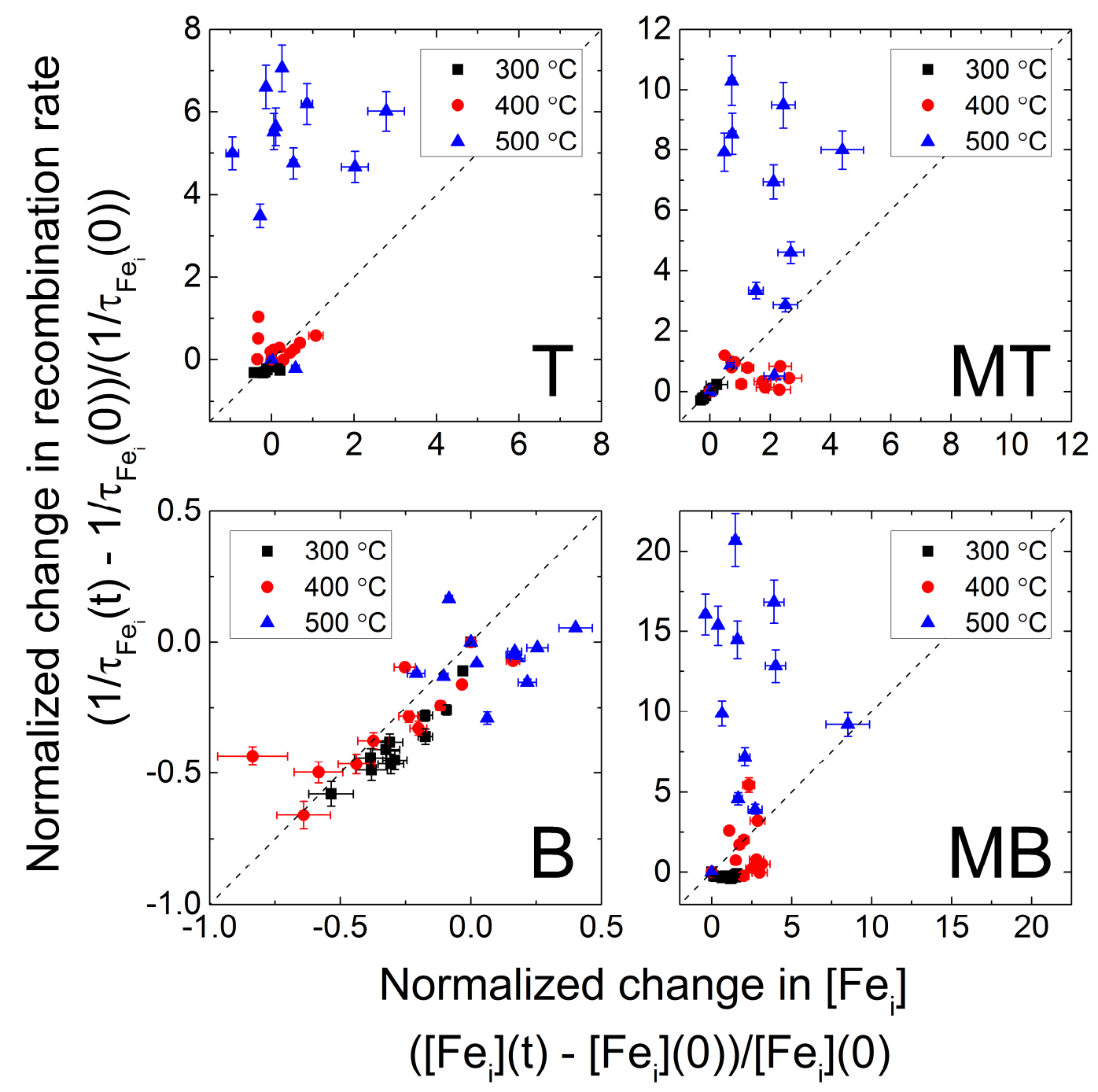

Figure 4. Normalized change in recombination rate versus normalized change in bulk interstitial iron concentration in accordance with Equation 1 for samples from the top (T), top middle (MT), bottom middle (MB) and bottom (B) of a mc-Si ingot. Dotted lines represent one-to-one correlation. Table 1. A summary of this study of low temperature annealing of mc-Si. The general qualitative trends in lifetime and bulk iron concentrations are stated. Any correlation between the two is stated.

\begin{tabular}{|c|c|l|c|c|}
\hline Temperature & Location & Lifetime trend & $\begin{array}{c}\text { Correlation between } \\
{\left[\mathbf{F e}_{\mathbf{i}}\right] \text { trend }} \\
\text { lifetime and [Fe } \mathbf{i} \text { change }\end{array}$ \\
\hline $300{ }^{\circ} \mathrm{C}$ & $\mathrm{T}$ & Increase (substantial) & Constant & No \\
\cline { 2 - 5 } & $\mathrm{MT}$ & Decrease (small) & Increase & Yes \\
\cline { 2 - 5 } & $\mathrm{MB}$ & Increase (small) & Increase & No \\
\cline { 2 - 5 } & $\mathrm{B}$ & Increase (substantial) & Decrease & Yes \\
\hline $400{ }^{\circ} \mathrm{C}$ & $\mathrm{T}$ & Decrease & Constant & No \\
\cline { 2 - 5 } & $\mathrm{MT}$ & Decrease (substantial) & Increase & No \\
\cline { 2 - 5 } & $\mathrm{MB}$ & Decrease (substantial) & Increase & No \\
\cline { 2 - 5 } & $\mathrm{B}$ & Increase (substantial) & Decrease & Yes \\
\hline $500{ }^{\circ} \mathrm{C}$ & $\mathrm{T}$ & Decrease (substantial) & Increase & No \\
\cline { 2 - 5 } & $\mathrm{MT}$ & Decrease (substantial) & Increase & No \\
\cline { 2 - 5 } & $\mathrm{MB}$ & Decrease (substantial) & Increase & Possible \\
\cline { 2 - 5 } & $\mathrm{B}$ & Constant & Constant & \\
\hline
\end{tabular}


Our work suggests there is potential for improving a sub-set of as-grown mc-Si wafers by long low temperature annealing. We have found that samples from the top and bottom of the block can be improved by annealing at $300{ }^{\circ} \mathrm{C}$, with $400{ }^{\circ} \mathrm{C}$ also improving bottom samples. Fig. 1 shows that lifetimes in bottom wafers have been increased to $22.9 \mu$ s from $9.7 \mu \mathrm{s}$ at $300{ }^{\circ} \mathrm{C}$, and to $31.7 \mu \mathrm{s}$ from $10.8 \mu \mathrm{s}$ at $400{ }^{\circ} \mathrm{C}$. A smaller improvement in top wafers was measured, with the increase being from $17.1 \mu \mathrm{s}$ to $22.9 \mu \mathrm{s}$. Experimental work on these samples is on-going, so further annealing may bring more improvement. Correlation with iron data (Fig. 4) shows that the improvement in bottom wafers is most likely due to redistribution of bulk iron. The lifetime images in Fig. 3 (a) demonstrate an improvement in the bulks of the grains. The destination of the bulk iron lost is the subject of further investigation. At $300{ }^{\circ} \mathrm{C}$ it is noted that the initial bulk iron level is about seven orders of magnitude above the extrapolated solid solubility [10, 20], so there could be sufficient driving force for nucleation of new iron-containing precipitates, but the annealing times are also sufficient for iron diffusion to existing precipitates (or possibly even to the surfaces [10]).

The studies of Krain et al. [11] and Liu and Macdonald [14] found a systematic reduction in bulk iron with annealing time. Krain et al. find the bulk iron concentration to decay in a way consistent with iron diffusion to crystallographic defects [11]. Our results are not generally consistent with those of Krain et al.. In many samples, particularly those from the middle of the block, we do not find a systematic decay in bulk iron concentration, and it some cases it appears to increase. Our working explanation for the discrepancy would involve bulk hydrogen present in the samples of Krain et al. but probably not in ours, but experiments to verify this are ongoing. The work of Karzel et al. supports a hypothesis involving hydrogen [16]. We can also cautiously compare our data to those of Liu and Macdonald [14], but note that their high temperature passivation step (45 minutes at $1000{ }^{\circ} \mathrm{C}$ ) will have had a substantial effect on the starting material. Liu and Macdonald suggest the hydrogenation level affects the decay rate of bulk iron, and our bulk iron decay data at $400{ }^{\circ} \mathrm{C}$ are much more similar to theirs with $\mathrm{SiO}_{2}$ passivation (very low hydrogen) than the $\mathrm{Al}_{2} \mathrm{O}_{3}$ passivation data (moderate hydrogen) and silicon nitride data of Krain et al. (relatively high hydrogen) they also consider.

\section{Conclusion}

The effect of low temperature annealing on the lifetime and bulk iron concentration in mc-Si has been studied with a view to understanding internal gettering. A temporary room temperature liquid iodine-ethanol passivation scheme is used to minimize the introduction of hydrogen into the bulk. Perhaps surprisingly, for wafers from the middle and top of a block it is found that annealing at 400 ${ }^{\circ} \mathrm{C}$ and $500{ }^{\circ} \mathrm{C}$ results in a lifetime reduction, and this cannot be explained only by the redistribution of bulk iron. Annealing at $300{ }^{\circ} \mathrm{C}$ improves the lifetime in relatively poor samples from the top and bottom of the block. Annealing at $400{ }^{\circ} \mathrm{C}$ also improves bottom samples. The improvement observed in bottom wafers correlates with the change measured in bulk iron concentration. These preliminary results show that long low temperature annealing can improve the minority carrier lifetime in some lower quality as-received mc-Si wafers.

\section{Acknowledgements}

This work was supported by a Royal Academy of Engineering/ EPSRC Research Fellowship, an EPSRC First Grant (EP/J01768X/2) and a Royal Society Research Grant (RG100076). Prof. P.R. Wilshaw and Dr S. Senkader are thanked for helpful discussions. 


\section{References}

[1] K. Bothe, R. Krain, R. Falster, R. Sinton, "Determination of the bulk lifetime of bare multicrystalline silicon wafers", Progress in Photovoltaics: Research and Applications 18, 204 (2010), doi: 10.1002/pip.975.

[2] T. U. Nærland, L. Arnberg, A. Holt, "Origin of the low carrier lifetime edge zone in multicrystalline PV silicon", Progress in Photovoltaics: Research and Applications 17, 289 (2009), doi: 10.1002/pip.876.

[3] S. P. Phang, D. Macdonald, "Direct comparison of boron, phosphorus, and aluminum gettering of iron in crystalline silicon", Journal of Applied Physics 109, 073521 (2011), doi: $10.1063 / 1.3569890$.

[4] M. Seibt, R. Khalil, V. Kveder, W. Schröter, "Electronic states at dislocations and metal silicide precipitates in crystalline silicon and their role in solar cell materials", Applied Physics A 96, 235 (2009), doi: 10.1007/s00339-008-5027-8.

[5] J. D. Murphy, K. Bothe, V. V. Voronkov, R. J. Falster, "On the mechanism of recombination at oxide precipitates in silicon", Applied Physics Letters 102, 042105 (2013), doi: $10.1063 / 1.4789858$.

[6] J. Hofstetter, D. P. Fenning, D. M. Powell, A. E. Morishige, T. Buonassisi, "Iron management in multicrystalline silicon through predictive simulation: Point defects, precipitates, and structural defect interactions", Solid State Phenomena 205-206, 15 (2014), doi: 10.4028/www.scientific.net/SSP.205-206.15.

[7] B. Ziebarth, M. Mrovec, C. Elsässer, P. Gumbsch, "Interstitial iron impurities at grain boundaries in silicon: A first-principles study", Physical Review B 91, 035309 (2015), doi: 10.1103/PhysRevB.91.035309.

[8] R. Falster, "Process for contamination removal and minority carrier lifetime improvement in silicon", US Patent No 5,272,119 (1993).

[9] K. J. Fraser, R. J. Falster, P. R. Wilshaw, "Cathodoluminescence assessment of annealed silicon and a novel technique for estimating minority carrier lifetime in silicon", Material Science and Engineering B 159-160, 194 (2009), doi: 10.1016/j.mseb.2008.05.006.

[10]J. D. Murphy, R. J. Falster, "The relaxation behaviour of supersaturated iron in single-crystal silicon at 500 to $750^{\circ} \mathrm{C} "$, Journal of Applied Physics 112, 113506 (2012), doi: $10.1063 / 1.4767378$.

[11]R. Krain, S. Herlufsen, J. Schmidt, "Internal gettering of iron in multicrystalline silicon at low temperature", Applied Physics Letters 93, 152108 (2008), doi: 10.1063/1.2987521.

[12]M. D. Pickett, T. Buonassisi, "Iron point defect reduction in multicrystalline silicon solar cells", Applied Physics Letters 92, 122103 (2008), doi: 10.1063/1.2898204.

[13] M. Rinio, A. Yodyunyong, S. Keipert-Colberg, Y. P. B. Mouafi, D. Borchert, A. MontesdeocaSantana, "Improvement of multicrystalline silicon solar cells by a low temperature anneal after emitter diffusion", Progress in Photovoltaics: Research and Applications 19, 165 (2011), doi: 10.1002/pip.1002.

[14]A. Y. Liu, D. Macdonald, "Precipitation of iron in multicrystalline silicon during annealing", Journal of Applied Physics 115, 114901 (2014), doi: 10.1063/1.4868587.

[15] Y. Boulfrad, A. Haarahiltunen, H. Savin, E. J. Øvrelid, L. Arnberg, "Enhanced performance in the deteriorated area of multicrystalline silicon wafers by internal gettering", Progress in Photovoltaics: Research and Applications 23, 30 (2015), doi: 10.1002/pip.2391.

[16]P. Karzel, P. Frey, S. Fritz, G. Hahn, "Influence of hydrogen on interstitial iron concentration in multicrystalline silicon during annealing steps", Journal of Applied Physics 113, 114903 (2013), doi: 10.1063/1.4794852.

[17]A. Liu, C. Sun, D. Macdonald, "Hydrogen passivation of interstitial iron in boron-doped multicrystalline silicon during annealing", Journal of Applied Physics 116, 194902 (2014), doi: $10.1063 / 1.4901831$. 
[18]R. A. Sinton, A. Cuevas, "Contactless determination of current-voltage characteristics and minority-carrier lifetimes in semiconductors from quasi-steady-state photoconductance data", Applied Physics Letters 69, 2510 (1996), doi: 10.1063/1.117723.

[19]J. D. Murphy, K. Bothe, M. Olmo, V. V. Voronkov, R. J. Falster, "The effect of oxide precipitates on minority carrier lifetime in p-type silicon", Journal of Applied Physics 110, 053713 (2011), doi: 10.1063/1.3632067.

[20] J. D. Murphy, R. J. Falster, "Contamination of silicon by iron at temperatures below $800^{\circ} \mathrm{C}^{\prime}$, Physica Status Solidi Rapid Research Letters 5, 370 (2011), doi: 10.1002/pssr.201105388.

[21]A. L. Blum, J. S. Swirhun, R. A. Sinton, F. Yan, S. Herasimenka, T. Roth, K. Lauer, J. Haunschild, B. Lim, K. Bothe, Z. Hameiri, B. Seipel, R. Xiong, M. Dhamrin, J. D. Murphy, "Inter-laboratory study of eddy-current measurement of excess-carrier recombination lifetime", IEEE Journal of Photovoltaics 4, 525 (2014), doi: 10.1109/JPHOTOV.2013.2284375. 